\title{
THE UPTAKE AND ELIMINATION OF KRYPTON AND OTHER INERT GASES BY THE HUMAN BODY ${ }^{1}$
}

\author{
By C. A. TOBIAS, H. B. JONES, J. H. LAWRENCE, AND J. G. HAMILTON \\ (From the Divisions of Medical Physics ${ }^{2}$ and Medicine, and the Radiation Laboratory, Univer- \\ sity of California, Berkeley, California)
}

\section{INTRODUCTION}

Chemically inert gases, such as nitrogen, helium, neon, argon, krypton and xenon, apparently do not participate at normal pressures in biochemical reactions of the human body. These gases are present in physical solution, chiefly in the body water and fat. In recent years much interest has been focused on the exchange of these gases between body fluids and external air, through the lungs, skin and intestinal wall. A number of important physiological processes may be studied by means of inert gas exchange measurements.

During rapid decompression from several atmospheres to one atmosphere or from one atmosphere to a fraction of an atmosphere the dissolved inert gases originally in equilibrium may become relatively supersaturated so that under certain conditions gas bubbles may form in the blood and tissues (1). These may exert mechanical pressure on nerve endings or may cause pain by some other mechanism (2). Our investigations were initiated with the explicit desire to provide (a) classification procedures for selection of high altitude flyers on the basis of gas exchange rates; $(b)$ information on methods of prevention of bends by accelerating the elimination of nitrogen or inert gas or by pre-breathing oxygen. In attempting to solve these two problems, which were of immediate practical importance, we could spend relatively little time on the study of the fundamental mechanisms of inert gas exchange. Answers to the problems $a$ and $b$ have been given elsewhere $(3,4)$ and the purpose of this paper is to describe some experiments which pertain to the mechanism of inert gas exchange in the human body.

1 These investigations were initiated originally through the support of the Columbia Foundation (Columbia Fund for Medical Physics) and subsequently supported through a contract recommended by the Committee on Medical Research between the Office of Scientific Research and Development and the University of California.

2 Of the Department of Physics.
After Zuntz (5) postulated a mechanism for the exchange of dissolved nitrogen between the tissues and the lungs, Boycott et al. (6) carried out experiments on goats and men subjected to excess pressure and determined the general shape of the nitrogen desaturation curve. Bornstein (7) and later Campbell and Hill $(8,9)$ made further studies of nitrogen exchange, showing that rates of exchange are different in various parts of the body. Shaw et al. (10) demonstrated on dogs that under conditions of equilibrium at pressures up to four atmospheres, the nitrogen content of the body is proportional to the partial pressure of nitrogen in the lungs, and that the nitrogen saturation time is the same as the desaturation time. Behnke et al. (11-14) also showed that the slope of the nitrogen elimination curve is a function of the cardiac output and suggested that helium exchange is faster, argon exchange slower than that of nitrogen, gas elimination more rapid from the fluid constituents of tissues, and slower from tissues high in fat, and showed that helium and nitrogen may diffuse slowly through the skin. Throughout most of the above described work the whole body elimination was studied more thoroughly than that of specific regions because of lack of suitable methods. Recently Ferris et al. (15) measured the nitrogen exchange in man by determining changes in nitrogen content of arterial and venous blood samples. They found that arterial blood reaches equilibrium with pulmonary nitrogen within a few minutes, while venous blood reaches equilibrium much more slowly. Whiteley et al. (16) observed the same in the femoral vessels of cats and found that exercise increases the rate of denitrogenation. During the war Smith and Morales also carried out some similar experiments (17-19). The mechanism of total body gas exchange was put on a new basis as a result of work by Jones and his collaborators (20) who demonstrated that diffusion plays very little role in the uptake of various gases by tissues, and that the rapidity of gas exchange depends mainly on the gas carrying power 
TABLE I

Properties of the radioactive inert gases suitable for biological investigations *

\begin{tabular}{|c|c|c|c|c|c|c|}
\hline \multirow{2}{*}{ Name } & \multirow{2}{*}{ Isotope } & \multirow{2}{*}{$\begin{array}{c}\text { Type of } \\
\text { radiation }\end{array}$} & \multicolumn{2}{|c|}{ Energy of radiation } & \multirow{2}{*}{ Half life } & \multirow{2}{*}{$\begin{array}{l}\text { Most important nuclear } \\
\text { reaction }\end{array}$} \\
\hline & & & Particles mev & $\gamma$ rays & & \\
\hline $\begin{array}{l}\text { Nitrogen } \\
\text { Argon } \\
\text { Argon } \\
\text { Krypton }\end{array}$ & $\begin{array}{r}13 \\
37 \\
41 \\
79,81\end{array}$ & $\begin{array}{l}\beta_{\mathrm{K}}^{+} \\
\beta^{-}, \gamma \\
\beta^{+}, \gamma\end{array}$ & $\begin{array}{c}\frac{1.24}{1.5} \\
\sim .9(30 \%) ; \\
0.6(70 \%)\end{array}$ & $\begin{array}{l}\text { no } \gamma \\
\text { no } \gamma \\
.37 \\
0.2\end{array}$ & $\begin{array}{l}9.93 \text { minutes } \\
34 \text { days } \\
110 \text { minutes } \\
34 \text { hrs. }\end{array}$ & $\begin{array}{l}\mathrm{C}^{12}(\mathrm{~d}, \mathrm{n}) \\
\mathrm{Cl}^{37}(\mathrm{~d}, 2 \mathrm{n}) \\
\mathrm{A}^{40}(\mathrm{~d}, \mathrm{p}) \\
\mathrm{Br}^{79,81}(\mathrm{~d}, 2 \mathrm{n})\end{array}$ \\
\hline Krypton & 85 & $\beta^{-}$ & 0.74 & no $\gamma$ & 9.4 yrs. & $\underset{\mathrm{Kr}}{\mathrm{Kr}}(\mathrm{n}, \gamma)$ \\
\hline $\begin{array}{l}\text { Xenon } \\
\text { Xenon } \\
\text { Radon }\end{array}$ & $\begin{array}{l}127 \\
133 \\
222\end{array}$ & $\begin{array}{l}\mathrm{e}^{-}, \gamma \\
\beta^{-}, \gamma, \mathrm{e}^{-} \\
\alpha^{-}\end{array}$ & $\begin{array}{l}0 . \overline{42} \\
5.486\end{array}$ & $\begin{array}{l}0.9 \\
0.085 \\
-t\end{array}$ & $\begin{array}{l}34 \text { days } \\
5.3 \text { days } \\
3.825 \text { days }\end{array}$ & $\mathrm{I}_{\mathrm{U}-\mathrm{n}}^{127}(\mathrm{~d}, 2 \mathrm{n})$ \\
\hline
\end{tabular}

* For references and details see G. T. Seaborg and I. Perlman, Table of isotopes. Rev. Med. Phys., 1948, 20, 585. Also see Way et al., Nucleonics, 2, No. 5, Part 2, May, 1948.

$\dagger \gamma$ rays from radioactive daughters.

of the blood, that is gas solubility in blood and the rate of perfusion of the tissues by blood.

\section{EXPERIMENTAL METHODS}

A glance at Table I shows that it is difficult to work with radioactive nitrogen because of its short half lifethe gases argon, krypton and xenon are much better suited for tracer investigations. Fortunately it is permissible to use these gases instead of nitrogen if suitable correction factors are applied in interpreting the results. Two kinds of corrections are needed. First one has to take account of the fact that the water and fat solubilities of these gases are different. A detailed analysis of these solubilities by Lawrence $e t$ al. (21) is summarized in Table II. In addition, another correction factor must be used whenever diffusion of these gases influences the rate of gas exchange. As predicted by Graham's Law, Jones et al. recently demonstrated that the noble gases diffuse through gelatin membranes at room temperature at rates which vary inversely with the square root of the molecular weights of the gases.

In the present series of tests the absolute amount of inert gases in the tissues was emphasized less than the relative rate of their uptake and desaturation. Prior to

TABLE II

Solubilities of inert gases in water and oils at $37^{\circ} \mathrm{C}$.

\begin{tabular}{|c|c|c|c|c|}
\hline \multirow{2}{*}{ Gas } & \multicolumn{4}{|c|}{$\begin{array}{l}\text { Bunsen's absorption coefficient } \\
\text { (two significant figures) }\end{array}$} \\
\hline & $\underset{\text { weight }}{\text { Molecular }}$ & Water & Olive oil & $\begin{array}{c}\text { Oil/water } \\
\text { solubility } \\
\text { ratio }\end{array}$ \\
\hline $\begin{array}{l}\text { Helium } \\
\text { Neon } \\
\text { Nitrogen } \\
\text { Argon } \\
\text { Krypton } \\
\text { Xenon } \\
\text { Radon }\end{array}$ & $\begin{array}{c}4 \\
20.2 \\
28 \\
39.9 \\
83.7 \\
131.3 \\
222\end{array}$ & $\begin{array}{l}0.0085 \\
0.0097 \\
0.013 \\
0.026 \\
0.045 \\
0.085 \\
0.15\end{array}$ & $\begin{array}{c}0.015 \\
\overline{.067} \\
.14 \\
.43 \\
1.7 \\
19.0\end{array}$ & $\begin{array}{r}1.7 \\
5.2 \\
5.3 \\
9.6 \\
20.0 \\
125.0\end{array}$ \\
\hline
\end{tabular}

uptake measurements the radioactive gases were introduced into a closed circuit spirometer. The concentration of gas in the spirometer was determined by a GeigerMueller counter. In most experiments this concentration was held constant throughout the period of radioactive gas uptake in the body. In this way the final volume of the spirometer did not enter into consideration when the rate of body uptake was determined. The simple method of measurement required placing a Geiger-Mueller counter against the body region studied and continuously recording the counting rate. ${ }^{3}$ The schematic setup is shown in Figure 1, Diagram 1a. A counter was held gently in one hand, surrounded by a lead shield, as shown in Figure 1, Diagram 1c, and the left knee was placed on a lead slit, limiting the solid angle of measurement for another counter (Figure 1, Diagram 1b).

Preparation of the radioactive gases in the cyclotron required special techniques. Except in the cases of $\mathrm{N}^{13}$, and $\mathrm{A}^{\mathbf{4}}$, halides were bombarded by deuterons; potassium chloride for $\mathrm{A}^{87}$, potassium bromide for $\mathrm{Kr}^{81}$, 70 and potassium iodide for $\mathrm{Xe}^{127}$. Because of the high intensity of the deuteron beam, it was necessary to design a target which spread the deuteron beam over a relatively large area so that heat generated could be dissipated. The target plate was tilted so that the effective portion of the beam was spread over an area of 30 square $\mathrm{cm}$. It was also found necessary to isolate the space above the target from the cyclotron vacuum because during bombardment a considerable amount of occluded gas may be released from the target and this would seriously hamper the maintenance of a proper degree of vacuum in the cyclotron as well as cause a loss of the radioactive noble gas formed during the period of exposure. Two thin aluminum windows, cooled by compressed air, were used. The space above the target (the so-called bell jar) was usually filled with $\mathrm{He}$ at $1 / 2$ atmospheric pressure. The target plates themselves were made of $1 / 4$ inch copper plate with a grooved surface. The halide salts were fused to the reduced surface of the target at a

3 These methods were developed in collaboration with J. B. Mohney and F. W. Loomis of this laboratory. 


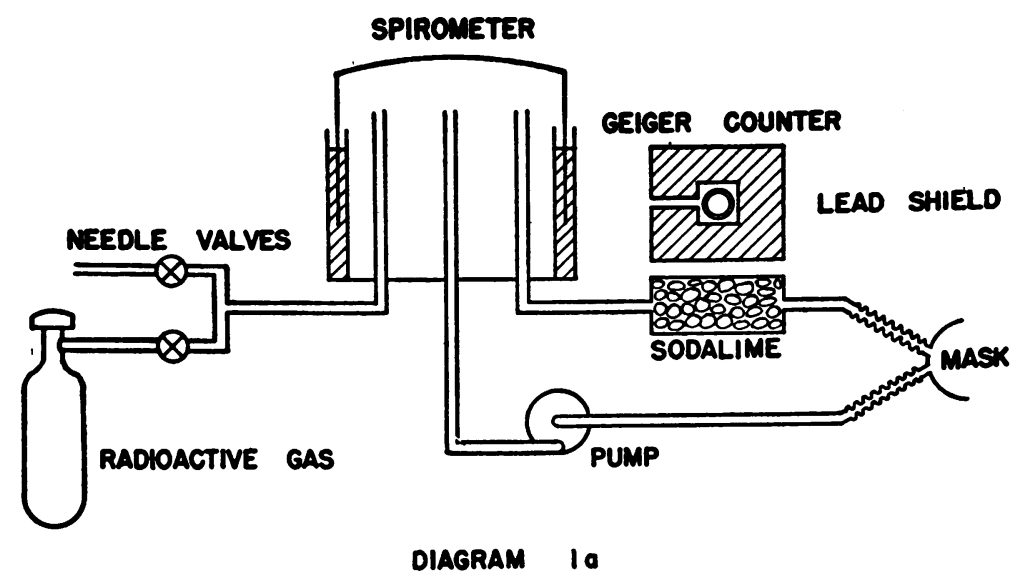

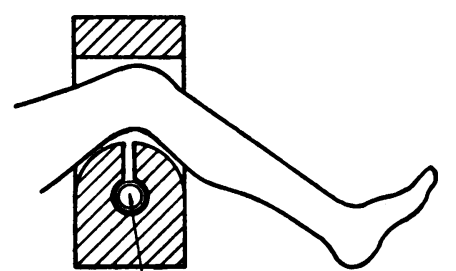

L G.M. COUNTER

LEAD SHIELD FOR MEASUREMENT OF ACTIVITY IN THE KNEE REGION

DIAGRAM IO
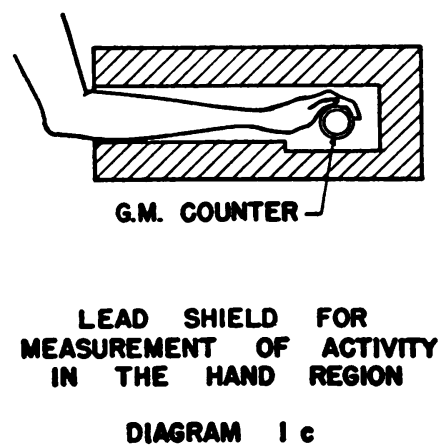

Fig. 1. Schematic View of the Apparatus Used for Radioactive Gas Exchange Measurements

Diagram 1 a. Spirometer, mask and gas recirculating system.

Diagram 1 b. Method of measuring radioactivity of the knee region.

Diagram 1 c. Method of measuring radioactivity in the hand region.

temperature of approximately $650^{\circ} \mathrm{C}$. In addition to potassium, halides of $\mathrm{Rb}, \mathrm{Sc}, \mathrm{Sr}$ and $\mathrm{Ba}$ have also been employed with no advantage over potassium salts. Lithium halides are undesirable because of their low melting points and hygroscopic properties, and sodium salts are not used because of the very intense gamma ray activity arising from $\mathrm{Na}^{24}$ after bombardment. About $10 \%$ of the radioactive inert gases was collected in the bell jar. The remainder is retained in the salt. The bombarded salt is usually scraped off the target plate and fused in a sealed evacuated quartz test tube. The occluded gas is easily driven off at a temperature of $650^{\circ} \mathrm{C}$. along with some halogen vapor contamination, usually radioactive (e.g., $\mathrm{Br}^{80}, 4.4$ hours.; $\mathrm{Br}^{82}, 34$ hours; $\mathrm{I}^{128}, 25$ minutes). These vapors are absorbed when passing through alkaline sodium sulfide solution. The radioactive inert gas along with some inactive helium and nitrogen is then collected in an evacuated bulb. In most experiments $1-2 \mathrm{~cm}^{3}$ of carrier gas was added, then the sample was compressed in a suitable bottle with pure oxygen to $-250 \mathrm{lbs} / \mathrm{sq}$. inch. Calibration of the radioactivity was accomplished by taking a known volume of mixed gas from the compressed sample and determin- ing its $\gamma$ activity in comparing it with a radium standard. During experimental use the gas flow was regulated by a needle valve, and the volume measured by a spirometer (see Figure 1). It is possible to salvage some of the long-life radioactive gases after each experiment for repeated use by collecting the entire expired air during the test, then re-absorbing it in silica gel at liquid air temperature. Recovery of the gases from the silica gel is carried out in the following manner. The silica gel is slowly heated, oxygen, nitrogen, and carbon dioxide are liberated first, followed by radioxenon or krypton. About $60 \%$ of the original radioxenon or krypton can be recovered by this method in the last liter of gas given off. Purification processes for somewhat different purposes are also described by Brown et al. (22).

The amount of radioactivity necessary for each uptake desaturation experiment was about 0.4 millicurie 4 and less than half this amount was absorbed in the body.

4 Since this work was done, the potential efficiency of gamma ray counting has been greatly increased by the use of fluorescence counters. This will allow the use of smaller radioactive samples in such experiments in the future. 
All data were corrected for radioactive decay by multiplying each counting rate by $e \lambda^{t}$ where $\lambda$ is the decay constant of the radioactive gas used; $t$ is the time elapsed since the beginning of the experiment.

\section{EXPERIMENTAL RESULTS}

The relative uptake and desaturation curves of the right hand and left knee were obtained by measuring the rate of gamma ray counts from them in function of time. A typical result obtained in two different experiments on the same person is shown in Figure 2. The counting rate was 3000/ minute near the peak of the curve. The experimental points did not fall exactly on the interpolated curves, due to random statistical fluctuations in the number of quanta emitted. If the subject moved during the experiment, other deviations in the measured counting rate occurred. For these reasons exact mathematical analysis of the data is not possible. At the beginning of the uptake experiments there usually was a delay between the time when breathing from the mask started and the time the first traces of radioactive gas appeared in the extremities. The delay amounted to 30 to 90 seconds and was due to the time required for mixing of the gases of alveolar air and spirometer (20 to 40 seconds half time) and transportation of the blood to the extremities. In searching for a suitable analytical expression for the shape of the uptake and desaturation curves we attempted to divide them into sums of simple exponential functions. The hand data could be satisfactorily approximated by the sum of three exponential functions. Analysis of the knee data makes it appear that the fastest of the three components has a negligible contribution so that the knee data, as well as total uptake data, may be described as the sum of two exponential functions of time. Unfortunately complete saturation of the hands or knees was not reached in the three hours maximum period of the "uptake" experiment. Because of discomfort of the subjects breathing the radioactive gas mixture from the somewhat uncomfortable masks, no attempts were made to follow the uptake longer than three hours. The desaturation, with the subject breathing air in a well ventilated room, was carried out up to 12 hours.

Four subjects participated in two consecutive tests each; in one test they inhaled radiokrypton at a constant concentration for a short period of

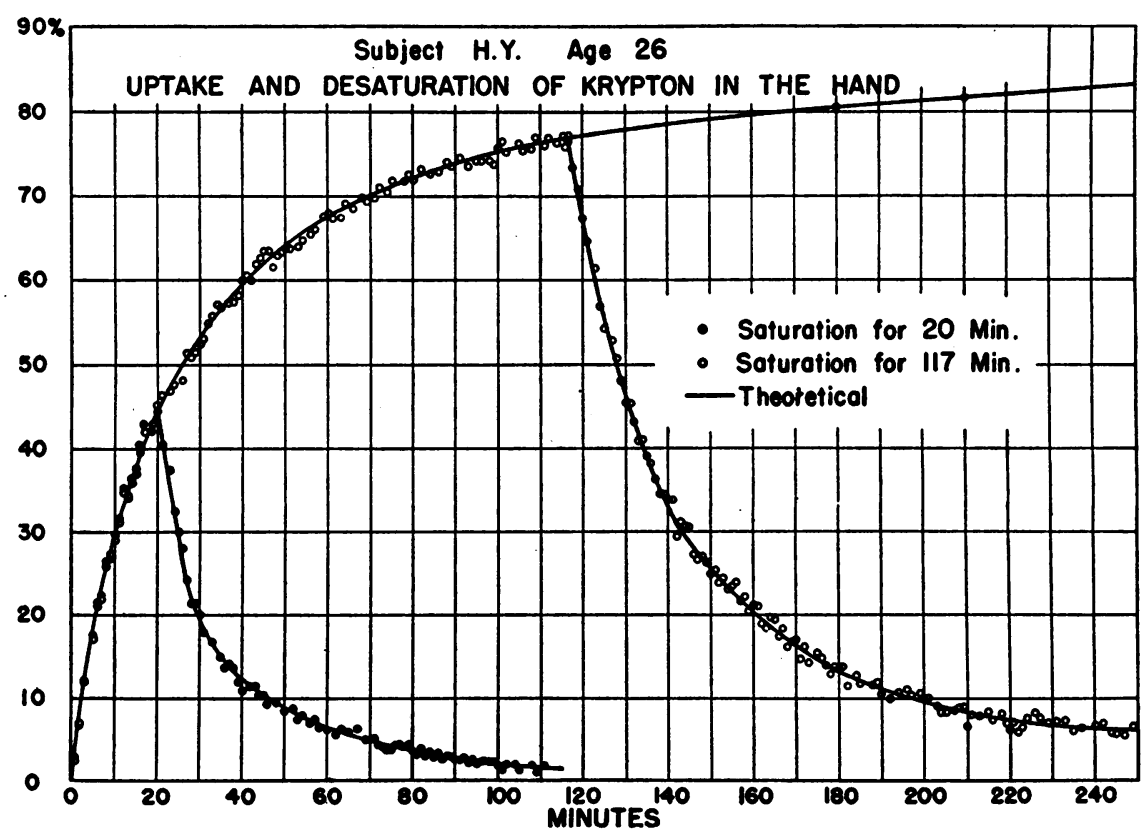

Fig. 2. Typical Uptake and Desaturation Experiments with Radiokrypton

The concentration of radioactive gas in the spirometer was held constant. The theoretical curves represent the sum of three exponents adjusted to the data as described in the text. 


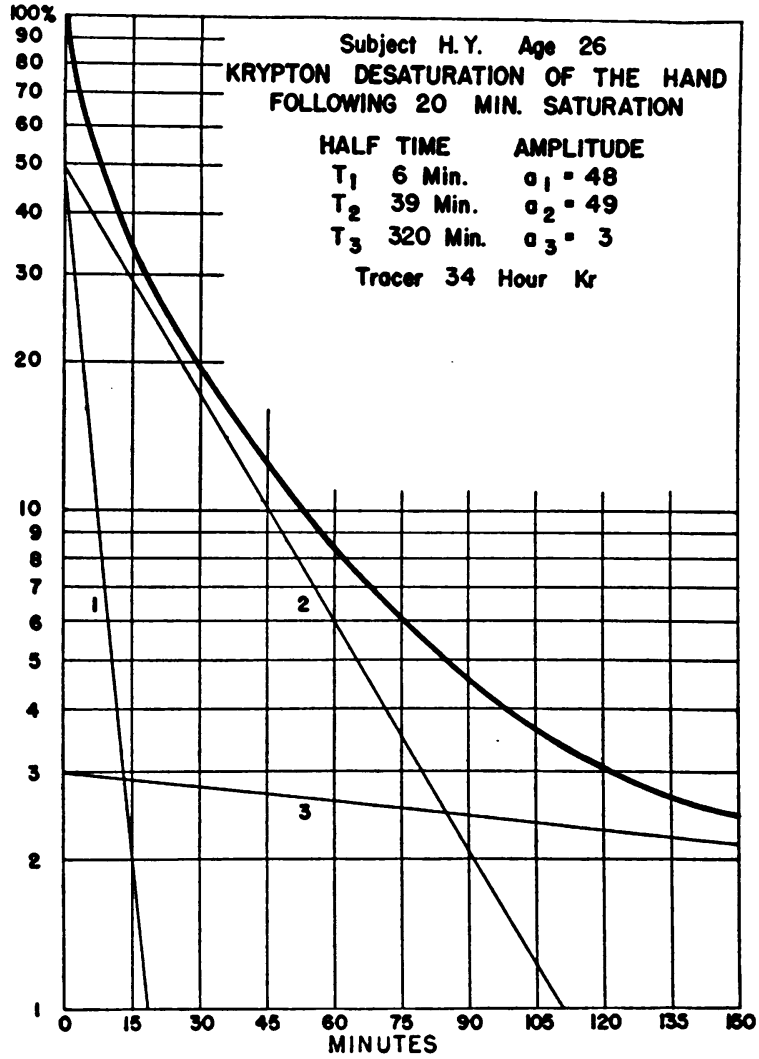

Fig. 3. Plot of Desaturation Curve on Semilogarithmic Paper After Saturation of SubJECT WITH RADIOKRYPTON FOR 20 MINUTES

The three components of desaturation are represented by straight lines.

time (about 30 minutes); the mask was then taken off and desaturation was continued by breathing air. In the second test, uptake was continued for about 120 minutes, followed by desaturation up to 12 hours.

Figure 2 shows the shape of the hand uptake and desaturation curves in two different experiments on the same subject. The uptake $\Phi$ in this and other experiments was found to fit the empirical formula:

$\Phi=A_{1}\left(1-2^{-\left(t / T_{2}\right)}\right)+A_{2}\left(1-2^{-\left(t / T_{2}\right)}\right)+A_{3}\left(1-2^{-\left(t / T_{2}\right)}\right)$

is the sum of three exponential type "saturation" curves. The "amplitudes" of these three components are $A_{1}, A_{2}$ and $A_{s}$ and the "half saturation times" characteristic of the rate of krypton uptake are $T_{1}, T_{2}$ and $T_{3}$; while $t$ is the time elapsed after the beginning of the gas uptake. The data are plotted in such a way that

$$
A_{1}+A_{2}+A_{8}=1 \text {. }
$$

The shape of the desaturation curves differs from the saturation curves, inasmuch as the desaturation after 20 minutes uptake does not follow exactly the same law as desaturation after 120 minutes uptake. To obtain some information regarding the analytical shape of the desaturation curves, they were plotted again in Figures 3-5 on semilogarithmic scale. It became clear the desaturation curves $\Psi$ may be expressed approximately as sums of three exponentially decaying functions of the form

$$
\Psi(\kappa, \tau)=a_{1} 2^{-\left(\tau / T_{\mathrm{d}}\right)}+a_{2} 2^{-\left(\tau / \mathrm{T}_{\mathrm{d}}\right)}+a_{8} 2^{-\left(\tau / \mathrm{T}_{\mathrm{d}}\right)} .
$$

Here $\kappa$ is the time taken for saturation; $a_{1}, a_{2}$, and $a_{s}$ are amplitudes again; $\tau$ is the time elapsed since beginning of desaturation; $T_{d 1}, T_{d s}, T_{d s}$ are characteristic desaturation half times. The measured values of some of the constants " $a_{1}$ " and $T_{d}$ are given in Table III. It is found by inspection of Table III, and similar data taken on other subjects, that the values $T_{d}$ are about the same irrespective of the length of time of uptake, while the amplitudes "a" are different for the two different experiments.

Comparing the constants of the uptake and desaturation experiments it was found that within reasonable agreement of the data obtained the constants expressing

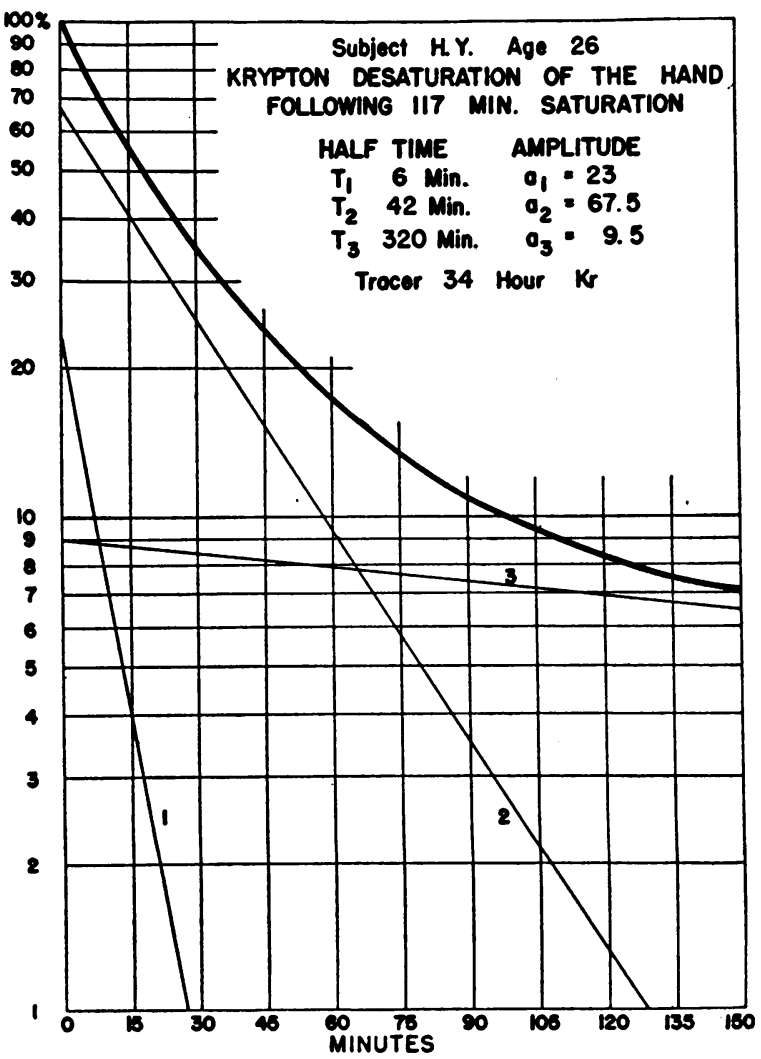

Fig. 4. Plot of Desaturation Curve on Semilogarithmic Paper After Saturation of Subject with RADIOKRYPTON FOR 117 MINUTES 


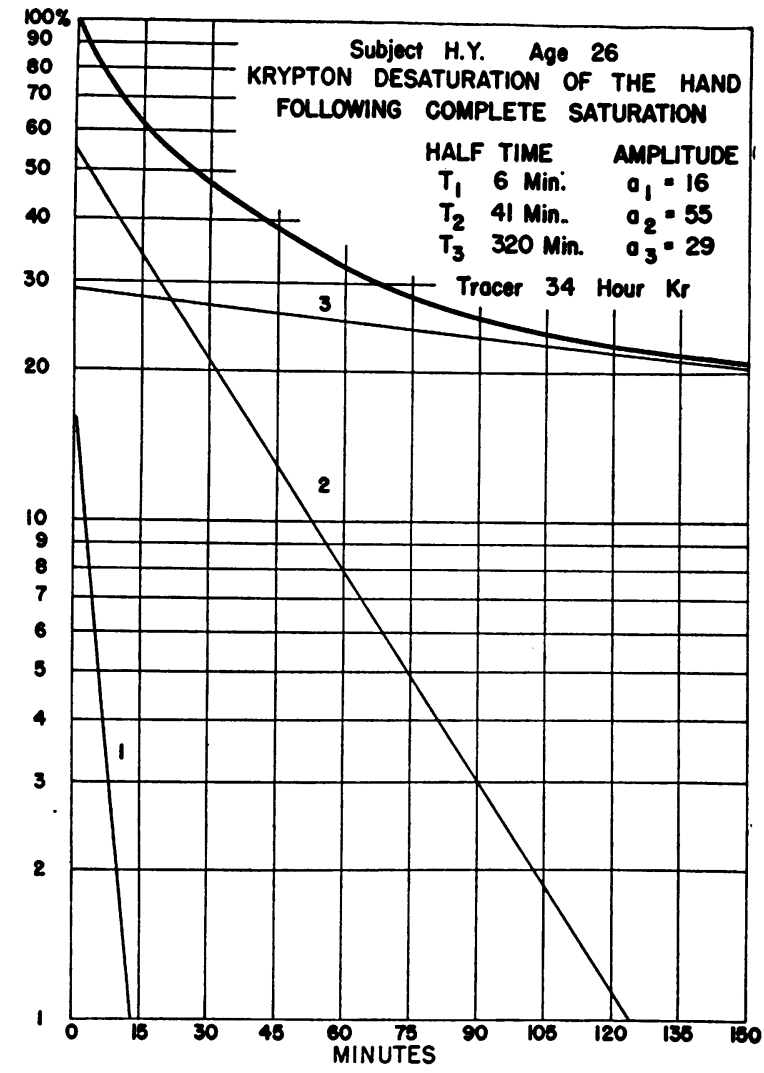

Fig. 5. Plot of Desaturation Curve on Semilogarithmic Paper After Complete Saturation OF SUbJECT With Radiokrypton

the empirical uptake curve and desaturation curve are related. First the half saturation and half desaturation times are about equal

$$
\begin{aligned}
& \mathrm{T}_{1} \approx \mathrm{T}_{\mathrm{d} 1}, \\
& \mathrm{~T}_{2} \approx \mathrm{T}_{\mathrm{d} 2}, \\
& \mathrm{~T}_{3} \approx \mathrm{T}_{\mathrm{d} 3} .
\end{aligned}
$$

Second, the amplitudes "a" of desaturation curves, obtained after saturation for time $\kappa$ obey the following approximate relationships:

$$
\begin{aligned}
& a_{1}=A_{1}\left(1-2^{-\left(\alpha / T_{1}\right)}\right), \\
& a_{2}=A_{2}\left(1-2^{-(\alpha / / 2)}\right), \\
& a_{3}=A_{3}\left(1-2^{-\left(\kappa / T_{3}\right)}\right),
\end{aligned}
$$

Consequently, using the constants obtained in uptake experiments, the empirical formula of desaturation after saturation may be obtained as

$$
\begin{aligned}
\Psi(\kappa, \tau) & =\mathrm{A}_{1}\left(1-2^{-\left(\kappa / T_{1}\right)}\right) 2^{-\left(\tau / T_{1}\right)} \\
& +A_{2}\left(1-2^{-\left(\kappa / T_{2}\right)}\right) 2^{-\left(\tau / T_{2}\right)}+A_{8}\left(1-2^{-\left(\kappa / T_{2}\right)}\right) 2^{-\left(\tau / T_{3}\right)} .
\end{aligned}
$$

Data obtained on four different subjects bearing on this point are given in Table IV. Further analysis of the

\begin{tabular}{|c|c|c|c|c|c|}
\hline \multicolumn{3}{|c|}{$\begin{array}{c}\text { Half desaturation } \\
\text { times } \tau\end{array}$} & \multicolumn{3}{|c|}{$\underset{a}{\text { Amplitudes }}$} \\
\hline & $\begin{array}{c}\tau=\text { after } \\
20 \text { minutes } \\
\text { uptake }\end{array}$ & $\begin{array}{c}\tau=\text { after } \\
117 \text { minutes } \\
\text { uptake }\end{array}$ & & $\begin{array}{c}\text { After } 20 \\
\text { minutes } \\
\text { uptake }\end{array}$ & $\underset{\substack{\text { minutes } \\
\text { uptake }}}{\text { After } 117}$ \\
\hline $\begin{array}{l}T_{1} \\
T_{2} \\
T_{3}\end{array}$ & $\begin{array}{c}\text { minutes } \\
6 \\
39 \\
310\end{array}$ & $\begin{array}{c}\text { minutes } \\
6 \\
42 \\
320\end{array}$ & $\begin{array}{l}\mathrm{a}_{1} \\
\mathrm{a}_{2} \\
\mathrm{a}_{3}\end{array}$ & $\begin{array}{l}.48 \\
.49 \\
.03\end{array}$ & $\begin{array}{l}.23 \\
.675 \\
.095\end{array}$ \\
\hline
\end{tabular}
data are possible along the lines of thought of Smith and Morales (17-19) or Tobias (23). These might result in better knowledge of the transport mechanisms involved.
TABLE III

Amplitudes and half desaturation times of the same $F \mathrm{r} r \mathrm{r}$ subject after different saturation times

It would appear then that saturation of the extremities with inert gases is not a strictly reversible phenomenon with desaturation as far as time dependence of the process goes. One may say that it appears as though in the hand there were at least three distinctly different reservoirs containing inert gas; they may be distinguished by the rapidity of the dissolved gas exchange. The filling of these three reservoirs is somewhat independent from each other inasmuch as the time

\begin{tabular}{|c|c|c|c|c|c|c|c|}
\hline & & $\begin{array}{l}A_{1} \\
\text { or } \\
a_{1}\end{array}$ & $\begin{array}{c}\mathrm{T}_{1} \\
\text { min. }\end{array}$ & $\begin{array}{c}A_{2} \\
\text { and } \\
\text { a2 }\end{array}$ & $\begin{array}{c}T_{2} \\
\text { min. }\end{array}$ & $\begin{array}{c}A_{8} \\
\text { and } \\
a_{3}\end{array}$ & $\begin{array}{c}\mathrm{T}_{3} \\
\text { min. }\end{array}$ \\
\hline H. Y. & $\begin{array}{l}\text { Uptake (117 minutes) } \\
\text { Desaturation after } 20 \\
\text { minutes uptake } \\
\text { Desaturation after } 117 \\
\text { minutes uptake }\end{array}$ & $\begin{array}{l}.16 \\
.49 \\
.23\end{array}$ & $\begin{array}{l}6 \\
6 \\
6\end{array}$ & $\begin{array}{l}.55 \\
.48 \\
.67\end{array}$ & $\begin{array}{l}42 \\
39 \\
42\end{array}$ & $\begin{array}{l}.29 \\
.03 \\
.10\end{array}$ & $\begin{array}{l}320 \\
320 \\
320\end{array}$ \\
\hline$\underset{24}{R . C .}$ & $\begin{array}{l}\text { Uptake (90 minutes) } \\
\text { Desaturation after } 20 \\
\text { minutes uptake } \\
\text { Desaturation after } 90 \\
\text { minutes uptake }\end{array}$ & $\begin{array}{l}.05 \\
- \\
.09\end{array}$ & 5 & $\begin{array}{r}.40 \\
.73 \\
.56\end{array}$ & $\begin{array}{l}39 \\
16 \\
39\end{array}$ & $\begin{array}{l}.55 \\
.17 \\
.35\end{array}$ & $\begin{array}{l}140 \\
140 \\
140\end{array}$ \\
\hline C. $\mathrm{T}$. & $\begin{array}{l}\text { Uptake } 165 \text { minutes } \\
\text { Desaturation after } 30 \\
\text { minutes uptake } \\
\text { Desaturation after } 165 \\
\text { minutes uptake }\end{array}$ & $\begin{array}{l}.10 \\
.20 \\
.12\end{array}$ & $\begin{array}{l}2 \\
2 \\
2\end{array}$ & $\begin{array}{l}.68 \\
.76 \\
.78\end{array}$ & $\begin{array}{l}17 \\
40\end{array}$ & $\begin{array}{l}.22 \\
.04 \\
.10\end{array}$ & $\begin{array}{l}315 \\
366 \\
315\end{array}$ \\
\hline$\underset{21}{\text { E. F. }}$ & $\begin{array}{l}\text { Uptake } 155 \text { minutes } \\
\text { Desaturation after } 102 \\
\text { minutes uptake } \\
\text { Desaturation after } 155 \\
\text { minutes uptake }\end{array}$ & $\begin{array}{l}.14 \\
.27 \\
.18\end{array}$ & $\begin{array}{l}8 \\
5 \\
8\end{array}$ & $\begin{array}{l}.67 \\
.68 \\
.73\end{array}$ & $\begin{array}{l}50 \\
47 \\
50\end{array}$ & $\begin{array}{l}.19 \\
.05 \\
.09\end{array}$ & $\begin{array}{l}267 \\
250\end{array}$ \\
\hline
\end{tabular}
of filling, as characterized by the half saturation time, falls in a definite range. The saturation of each reservoir may be at the present state of experimental accuracy, expressed by a single exponential type function.

TABLE IV

Constants of uptake 
TABLE V

Uptake of krypton gas in the hand

\begin{tabular}{|c|c|c|c|c|c|c|c|c|}
\hline \multirow{2}{*}{ Name } & \multirow{2}{*}{ Age } & \multicolumn{2}{|c|}{ First component } & \multicolumn{2}{|c|}{ Second component } & \multicolumn{2}{|c|}{ Third component } & \multirow{2}{*}{$\begin{array}{c}\text { Bends } \\
\text { suscepti } \\
\text { bility }\end{array}$} \\
\hline & & Amplitude & Half time & $\mathbf{A}_{2}$ & $T_{2}$ & As & $T_{3}$ & \\
\hline $\begin{array}{l}\text { M. C. } \\
\text { E. W. } \\
\text { G. B. } \\
\text { E. F. } \\
\text { S. C. } \\
\text { D. D. } \\
\text { R. G. } \\
\text { C. T. } \\
\text { H. Y. }\end{array}$ & $\begin{array}{l}17 \\
18 \\
20 \\
21 \\
21 \\
21 \\
24 \\
25 \\
26\end{array}$ & $\begin{array}{l}.19 \\
.13 \\
.17 \\
.14 \\
.06 \\
.05 \\
.10 \\
.16\end{array}$ & $\begin{array}{c}\text { minutes } \\
3 \\
6 \\
5 \\
8 \\
4 \\
5 \\
2 \\
6\end{array}$ & $\begin{array}{l}.66 \\
.59 \\
.61 \\
.66 \\
.65 \\
.14 \\
.40 \\
.68 \\
.55\end{array}$ & $\begin{array}{c}\text { minutes } \\
32 \\
35 \\
40 \\
50 \\
32 \\
13 \\
39 \\
40 \\
42\end{array}$ & $\begin{array}{l}.15 \\
.28 \\
.22 \\
.20 \\
.29 \\
.86 \\
.55 \\
.22 \\
.29\end{array}$ & $\begin{array}{c}\text { minutes } \\
100 \\
145 \\
129 \\
315 \\
104 \\
125 \\
140 \\
315 \\
320\end{array}$ & $\begin{array}{l}\mathbf{r} \\
\mathbf{r} \\
\mathbf{s} \\
\mathbf{s} \\
\mathbf{s} \\
\mathbf{r} \\
\mathbf{s} \\
\mathbf{i} \\
\end{array}$ \\
\hline Average & 21.4 & .11 & 4.3 & .54 & 33 & .35 & 188 & \\
\hline
\end{tabular}

$\mathbf{r}=$ relatively resistant. $\mathrm{s}=$ susceptible. $\mathrm{i}=$ intermediate.

Examining the three components in a typical uptake curve one might say that the fastest component probably has something to do with the inert gas exchange between blood and very vascularized tissues. The $1 / 2$ saturation time $\left(T_{1}\right)$ for this component appears to be $\sim$ two to 10 minutes for the hand. This component of the hand curve accounts in intensity for 2 to $15 \%$ of the total radioactive gas content. Its rapidity is in good agreement with the direct findings of Cook and Sears (24) on dogs, and Ferris et al. (15) for humans. They find that exchange of inert gases (krypton in dogs, nitrogen in humans) with arterial blood is rapid; one passage of blood through the lungs is enough to empty or fill it with gases to $\sim 80$ to $95 \%$ of the equilibrium value. After a few seconds of transport time the arterial blood enters the hand; in its passage through the capillaries, it uploads most of the radioactive gas to the tissues and returns as venous blood empty of gas to the lungs where it takes up more. The characteristic of this component is its variability in half saturation time, or amplitude; this is to be expected and further data regarding it will be presented below. In the knee region this component may be found only with a very small amplitude: the amount of dissolved gases in blood at the knee region is small compared to the amount dissolved in the water and fat, due to the relatively lesser vascularity.

The second component of the inert krypton uptake has a half saturation time $T_{2}$ between 10 and 40-50 minutes in the hand and between 35 and 72 minutes in the knee. The amplitude of this com- ponent in a group of young persons varies between 50 and $66 \%$ of the total for the hand and 17 and $42 \%$ in the knee region. If there were no third component, to all practical purposes complete saturation of the hand would be reached in about 90 minutes and 150 minutes in the knee.

The third component for the hand has 100 to 320 minutes half time, with the amplitude between 35 and 55\%. $\mathrm{T}_{3}$ varies between 190 and 870 minutes in the knee with an amplitude variation of 61 to $90 \%$.

Table $\mathrm{V}$ shows a set of hand data taken on different subjects and Table VI shows the constants of the knee region taken on seven subjects. In the same tables the susceptibility to decompression sickness is shown, as determined in repeated ascents in the decompression chamber by standard exercise methods. Though gas ex-

TABLE VI

Uptake of krypton in the knee region

\begin{tabular}{|c|c|c|c|c|c|c|}
\hline \multirow{3}{*}{ Name } & \multicolumn{5}{|c|}{$A_{1}, T_{1}$ : Small } & \multirow{3}{*}{$\begin{array}{l}\text { Bends } \\
\text { suscepti- } \\
\text { bility }\end{array}$} \\
\hline & \multirow{2}{*}{ Age } & \multicolumn{2}{|c|}{ First component } & \multicolumn{2}{|c|}{$\begin{array}{l}\text { Second } \\
\text { component }\end{array}$} & \\
\hline & & $\mathbf{A}_{2}$ & $T_{2}$ & $\mathbf{A}_{\mathbf{3}}$ & $T_{3}$ & \\
\hline $\begin{array}{l}\text { E. F. } \\
\text { G. B. } \\
\text { W. C. } \\
\text { M. Ch. } \\
\text { G. J. } \\
\text { S. C. } \\
\text { C. T. }\end{array}$ & $\begin{array}{l}21 \\
20 \\
21 \\
21 \\
19 \\
21 \\
25\end{array}$ & $\begin{array}{l}.41 \\
.41 \\
.11 \\
.39 \\
.29 \\
.17 \\
.43\end{array}$ & $\begin{array}{c}\text { minutes } \\
60 \\
54 \\
36 \\
48 \\
67 \\
72 \\
50\end{array}$ & $\begin{array}{l}.59 \\
.59 \\
.89 \\
.61 \\
.71 \\
.71 \\
.57\end{array}$ & $\begin{array}{c}\text { minutes } \\
870 \\
230 \\
440 \\
190 \\
270 \\
220 \\
600\end{array}$ & $\begin{array}{l}\mathbf{s} \\
\mathbf{s} \\
\mathbf{i} \\
\mathbf{r} \\
\mathbf{i} \\
\mathbf{s} \\
\mathbf{i}\end{array}$ \\
\hline Average & 21 & .32 & 55 & .64 & 400 & \\
\hline
\end{tabular}


change has a bearing on the development of decompression sickness, there is no obvious correlation in the data presented. It has been shown with other methods that total resting nitrogen exchange has correlation to bends, but also that there are other important factors to consider (e.g., state of exercise).

The gas exchange curves presented in this paper are reproducible to a certain extent. This conclusion is based on repetitions of the experiment in four subjects. It would appear that under identical experimental conditions and with less than a month interval between consecutive measurements the individual variations of the amplitudes and time constants are less than the variations in a group of the same age. It is essential, however, to note that a change in physiological condition may cause a considerable change in the shape of the gas exchange curve, especially that of the hand.

A number of experimental conditions were provided to study such changes; these proved valu-

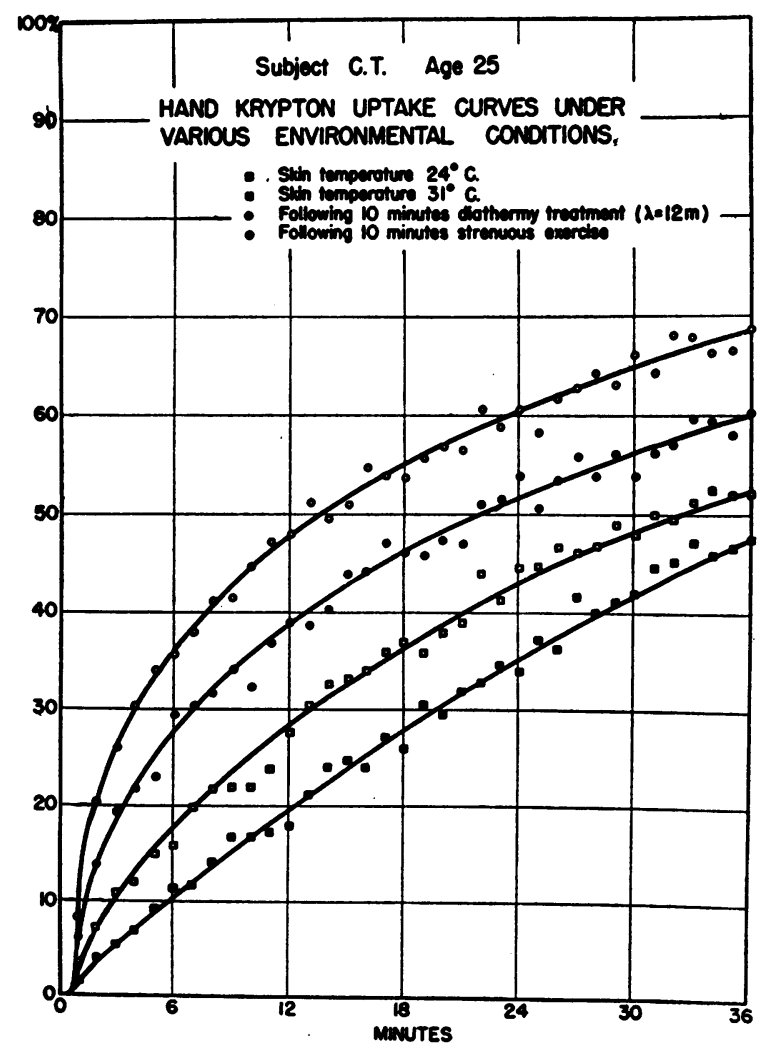

Fig. 6. Variations in the Hand Uptake Curve of a Subject Under Various Environmental Conditrons

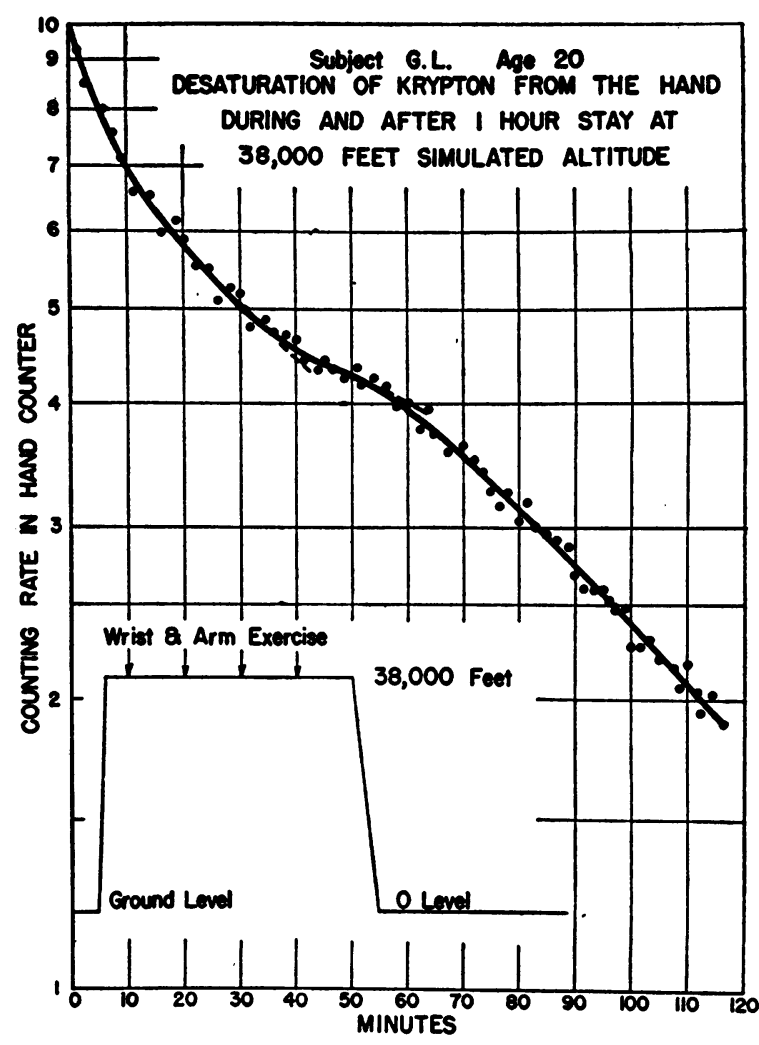

Fig. 7. Demonstration of Retardation in the KRYPton Elimination of the Hand DuRing a High Altitude Flight

The rate of elimination returned to normal after return to ground level. Note inflexion in the curve.

able in the interpretation of data. The uptake and desaturation curve of radiokrypton was influenced easiest in the hand. On subjects with cold hands usually a characteristically low gas exchange rate was obtained. This phenomenon appears to be due to a vasoconstriction of the surface blood vessels of the hand. In terms of the exponential components of the uptake curve : $A_{1}$ decreased by a factor of three or four (see Figure 6). Diathermy heating of the hand for 10 minutes with a 12 meter wavelength machine increased $A_{1}$ above normal, as shown in Figure 6, and it appeared to decrease $T_{2}$. Heavy exercise just prior to the test (10 minutes of fast bicycle riding) increased $A_{1}$ to about twofold normal. Administration of adrenaline ( $0.5 \mathrm{cc}$. of $1 / 1000$ adrenaline) had the same effect as cold skin temperature. We may thus conclude that rapidity of krypton exchange reflected the state of the vascular bed of the hand. No extensive tests were carried out for the knee 
region; it was apparent, however, that the changes were considerably less in magnitude.

The rate of radioactive krypton and argon uptake was studied in a large group of young subjects in short, half-hour tests. An index was derived from these data and correlated with the incidence and severity of decompression sickness. It was found that after exposure to low atmospheric pressure, when the subjects were totally at rest in the decompression chamber, the coefficient of correlation was very high: those with low gas exchange rates got the bends, in contrast to the correlation with the incidence of decompression sickness after exercise (e.g., Tables V and VI) when it was low. Since the blood flow or the carrying capacity of blood is an important factor in the rapidity of the exchange, we attempted to see whether in some way this carrying capacity could be increased. Since nitrogen and krypton are much more soluble in fats and oils than in water, it was thought that lipemia occurring some two hours after ingestion of a fatty meal might help to increase the rapidity of gas exchange, and thus relieve the danger from decompression sickness. Three subjects were given a test of three hours duration two hours after ingestion of a heavy fatty meal. ${ }^{5}$ The rapidity of gas exchange of the hand was not altered in these experiments.

In view of the correlation found between skin temperature of the hand and subsequent development of bends pain we attempted to detect a change in the rate of krypton exchange of the hand during decompression chamber tests. Five subjects were taken to 35,000 feet equivalent altitude for an hour to study the rapidity of krypton desaturation. All these subjects had breathed pure oxygen. Three of the subjects were free from bends pain: their desaturation curve remained normal. One subject, who on many previous occasions invariably developed bends pain in the right shoulder, showed definite slowing down of the rate of hand gas exchange in the decompression chamber, though during his 60 minute stay at high altitude he did not have any pain. The fifth subject, whose desaturation curve is plotted in Figure 7, had incapacitating bends in his left knee, right shoulder, elbow and wrist during the time his gas exchange was measured. There was again a definite slowing

\footnotetext{
5 This consisted of one milkshake, $1 / 4 \mathrm{lb}$. of butter and one pint of cream.
}

of his desaturation curve in the decompression chamber. After reaching normal atmospheric pressure, the gas rate of krypton exchange curve rapidly reached normal. The changes observed fitted quite well with the general conclusions regarding the state of the circulation in decompression sickness in a different set of experiments (25), but they were not early enough or pronounced enough to be suitable for a preselection test.

It was of some interest to compare the rate of gas exchange observed on the hand of the same subject using different gases : radioactive nitrogen, argon, krypton and xenon. While we are in possession of some data more work needs to be done. The rate of gas exchange as far as components $T_{1}$ and $T_{2}$ were concerned seemed to be proportional to the solubility of each gas in water, in agreement with Jones' findings for total body uptake. $T_{3}$, however, in the case of xenon appeared to be somewhat larger than the value predicted from solubility considerations alone.

The inert gases dissolved in the body fluids may exchange with the external atmosphere through tissues other than the lungs. Behnke and his collaborators have shown that a small fraction of total helium exchange of the body occurs through the pores of the skin (13). The mucous membranes of the intestines, especially those of the duodenum, play an important role in the secretion of a number of substances. It seemed to be of some interest to test the distribution of gases through these membranes. The gas was introduced to the duodenum by a duodenal tube. A small fraction of the gas from the duodenum rapidly got into the circulation and appeared in the extremities as well as in the exhaled air. A gamma ray counter held in one of the subject's hands recorded the rate of rise of radioactivity in the hand, and the concentration in the exhaled air was indicated by another Geiger counter tube within the spirometer. The three curves obtained on three subjects indicate that in about 15 minutes the concentration of radioactive gas in the hand reached peak value. The curves obtained show wide variation when compared with each other, however, and it is not certain whether they indicate the rapidity of uptake through the duodenal wall or whether they also depend on the nature of the aggregation of gas bubbles within the intestinal space itself. Similar experiments were performed 


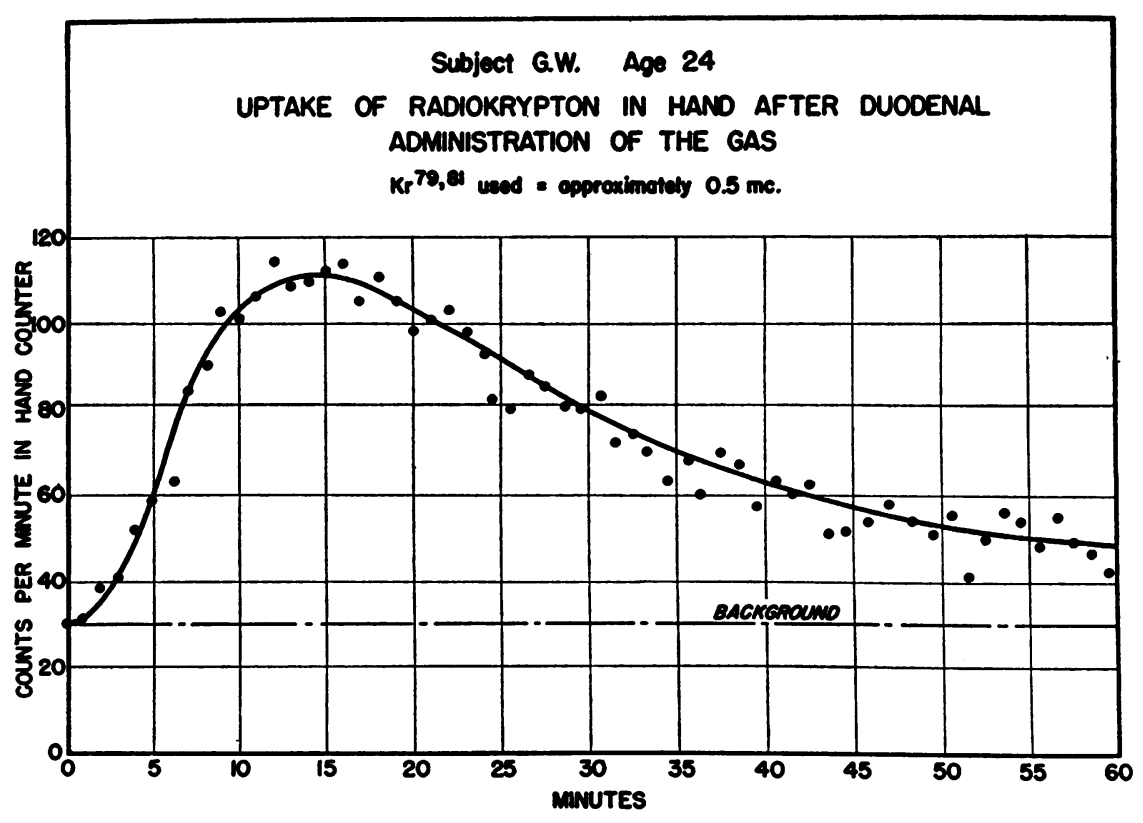

Fig. 8. Uptake of Radiokrypton in Hand After Duodenal Administration of About 0.5 MC. KRYPTON

with the gas administered to the stomach and to the large intestines. In these latter cases the uptake was not measurable within the first $30 \mathrm{~min}$ utes. The rapid exchange of gases from the intestinal tract to the circulation gives good support for recent methods of treatment for intestinal distention. If such intestinal gas consists mainly of nitrogen, then the excess gas will be absorbed by the circulation more rapidly if the patients are given pure oxygen. After a number of minutes of oxygen breathing, the dissolved nitrogen in the body becomes unsaturated and the nitrogen uptake from the intestines becomes accelerated. Other radioactive isotopes may also be used in this way to study the rate of exchange through the intestinal wall in normal and pathological conditions.

\section{SUMMARY}

The rate of change of radioactive krypton concentration in the extremities of young male subjects has been studied. If the subjects breathed a constant concentration of radiokrypton, mixed with oxygen, the uptake and desaturation curves could be satisfactorily expressed as the sum of not more than three superimposed components, changing as the simple exponential function of time.

Exercise or heating of the hand prior to the gas exchange resulted in a generally faster ex- change. Vasoconstriction or adrenaline caused slower exchange. A fatty meal eaten two hours before the krypton exchange had no effect on the rapidity of the test.

The gas exchange of some subjects slowed down while at 35,000 feet simulated altitude, breathing oxygen. Radioactive krypton, administered via stomach tube appeared rapidly in the circulation of the extremities and in the exhaled air of the lungs.

The techniques and results reported suggest that these radioactive gases have applications in the study of the circulation to the extremities in the living patient and in numerous problems of gas exchange in normal and pathologic states.

\section{ACKNOWLEDGMENTS}

The authors wish to thank the 60 inch cyclotron crew in Berkeley for the preparation of the radioactive gases; also Drs. W. F. Loomis and J. B. Mohney for participating in the early phases of this work.

\section{BIBLIOGRAPHY}

1. Cathpole, H. R., and Gersch, I., Pathogenetic factors and pathological consequences of decompression sickness. Physiol. Rev., 1947, 27, 360.

2. Lund, D. W., and Lawrence, J. H., Studies of the cause of pain in high altitude "bends." Federation Proc., 1946, 5 (1), 66. 
3. Jones, H. B., Preoxygenation and nitrogen elimination (A part of a monograph of decompression sickness, to be published by the Committee on Medical Research of the O. S. R. D.). In press.

4. Committee on Aviation Medicine of the O. S. R. D., National Research Council, Reports No. 51, May 29, 1942 ; No. 81, Dec. 1942 ; No. 176, Sept 2, 1943 ; No. 264, Dec. 2, 1943.

5. Zuntz, N., Zur Pathogenese und Therapie der durch rasche. Luftdruckänderungen erzeugten Krankheiten. Fortschr. d. Med., 1897, 15, 632.

6. Boycott, A. E., Damant, G. C. C., and Haldane, J. S., The prevention of compressed-air illness. J. Hyg., 1908, 8, 342.

7. Bornstein, A., Weitere Untersuchungen uber das Herzschlagvolumen. I. Mittheilung: Methodik; Warme Bäder. Ztschr. f. Exper. Path, und Therap., 1913, 14, 135.

8. Campbell, J. H., and Hill, L., Concerning the amount of nitrogen gas in the tissues and its removal by breathing almost pure oxygen. J. Physiol., 1931, 71, 309.

9. Campbell, J. A., and Hill, L., Studies in saturation of the tissues with gaseous nitrogen. I. Rate of saturation of goats' bone-marrow in vivo with nitrogen during exposure to increased atmospheric pressure. Quart. J. Exper. Physiol., 1933, 23, 197.

10. Shaw, L. A., Behnke, A. R., Messer, A. C., Thompson, R. M., and Motley, E. P., The equilibrium time of the gaseous nitrogen in the dog's body following changes of nitrogen tension in the lungs. Am. J. Physiol., 1935, 112, 545.

11. Behnke, A. R., Thompson, R. M., and Shaw, L. A., The rate of elimination of dissolved nitrogen in man in relation to fat and water content of body. Am. J. Physiol., 1935, 114, 137.

12. Behnke, A. R., and Yarbrough, O. D., Physiologic studies of helium. U. S. Nav. M. Bull., 1938, 36, 542.

13. Behnke, A. R., and Willmon, T. L., Gaseous nitrogen and helium elimination from the body during rest and exercise. Am. J. Physiol., 1941, 131, 619.
14. Willmon, T. L., and Behnke, A. R., Nitrogen elimination and oxygen absorption at high barometric pressures. Am. J. Physiol., 1941, 131, 633.

15. Ferris, E. B., Molle, W. E., and Ryder, H. W., Nitrogen exchange in tissue components of man. Committee on Aviation Medicine of the $\mathrm{O}$. $\mathrm{S}$. R. D., National Research Council, Report No. 60, July 15, 1942.

16. Whiteley, A. H., McElroy, W. D., Warren, G. H., and Harvey, E. N., Bubble formation in animals; denitrogenation. J. Cell. \& Comp. Physiol., 1944, 24, 257.

17. Smith, R. E., and Morales, M. F., On the theory of blood-tissue exchanges. I. Fundamental equations. Bull. Math. Biophys., 1944, 6, 125.

18. Morales, M. F., and Smith, R. E., The physical factors which govern gas exchange. Bull. Math. Biophys., 1945, 7, 106.

19. Smith, R. E., and Morales, M. F., On the theory of blood-tissue exchanges. II. Applications. Bull. Math. Biophys., 1944, 6, 133.

20. Jones, H. B., Gas exchange, circulation and diffusion; in: Otto Glasser's Medical Physics, Vol. II. Year Book Pub. Co., in press.

21. Lawrence, J. H., Loomis, W. F., Tobias, C. A., and Turpin, F. H., Preliminary observations on the narcotic effect of xenon with a review of values for solubilities of gases in water and oils. J. Physiol., 1946, 105, 197.

22. Brown, S. C., Irvine, J. W., Jr., and Livingston, M. S., Cyclotron targets: preparation and radiochemical separation. II. Krypton. J. Chem. Phys., 1944, 12, 132.

23. Tobias, C. A., Determination of the rate of biochemical reactions. Bull. Am. Phys. Soc., 1949, 24 (2), 8.

24. Cook, S. F., and Sears, W. N., Studies on the cardiovascular system of dogs with radioactive inert gases. Am. J. Physiol., 1945, 144, 164.

25. Tobias, C. A., Loomis, W. F., and Lawrence, J. H., Studies on skin temperature and circulation in decompression sickness. Am. J. Physiol, 1947, 149, 626. 